\title{
Anti-Growth Factors Associated with Pleurotus ostreatus in a Submerged Liquid Fermentation
}

\author{
Juliet B. Akinyele $^{1 *}$; Soji Fakoya ${ }^{2}$, and Clement F. Adetuyi ${ }^{1}$ \\ ${ }^{1}$ Department of Microbiology, Federal University of Technology, P.M.B 704, Akure, Ondo State, Nigeria \\ ${ }^{2}$ Department of Biological Sciences, Joseph Ayo Babalola University, Ikeji \\ Arakeji, P.M.B 5006, llesa, Osun State, Nigeria. \\ E.mail: akinyelejuliet@yahoo.com
}

Received 19 September 2011; Received in revised form 13 March 2012; Accepted 15 March 2012

\begin{abstract}
Aims: Previous studies had revealed that cultivation of Pleurotus ostreatus is often met with a lot of challenges ranging from environmental to biological factors which adversely affect the successful cultivation of the mushroom. Hence, a need to determine factors against mycelia colonization of substrate during mushroom's cultivation.

Methodology and Result: Conventional streak method was employed to establish the percentage inhibition as well as intercolony distance between the test organisms obtained from the infected substrate and mycelia of the mushroom during substrate colonization. The test organisms are: a fungus, Kutilakesopsis macalpineae and a bacterium, Pseudomonas tolaasii. The effect of $\mathrm{pH}$ and temperature on the mycelia growth of $P$. ostreatus was also investigated. There was a gradual increase in the percentage inhibition from $33.3 \%$ at $24 \mathrm{~h}$ to $75.0 \%$ at $168 \mathrm{~h}$ for $\mathrm{K}$. macalpineae and $37.5 \%$ at $24 \mathrm{~h}$ to 70.0 at $168 \mathrm{~h}$ for $P$. tolaasii. The inter-colony distance between the antagonists and the mushroom mycelium gradually decreased. Optical density of the mycelium growth was at its optimum at $\mathrm{pH} 4.5$ and temperature of $25{ }^{\circ} \mathrm{C}$ respectively. In vitro study also showed a significant increase in the optical density from $0.855 \pm 0.03$ at $24 \mathrm{~h}$ to $1.316 \pm 0.02$ at $168 \mathrm{~h}$ in the absence of test antagonist as against $0.812 \pm 0.06$ and $0.79 \pm 0.02$ at $24 \mathrm{~h}$ to $1.103 \pm 0.03$ and $0.902 \pm 0.03$ at $168 \mathrm{~h}$ when K. macalpineae and P.tolaasii were used as test antagonistic respectively.

Conclusion, significance and impact of study: Sterilization of substrate is essential to avoid contamination during mycelia colonization. Also, slightly acidic medium and temperature control is necessary for high yield of fruit bodies.
\end{abstract}

Keywords: Antigrowth, bio-factors, optical density, submerged fermentation

\section{INTRODUCTION}

Over years, the economic production of mushroom has been considered important and the interest for the control and improvement of the culturing technology for the edible ones has gained an unequivocal and considerable attention. Chang (1999) reported Pleurotus spp. as one of the valuable and edible mushrooms. It occupies the third place in the world's production of edible mushrooms, after Agaricus bisporus and Lentinula edodes, however, in recent years; it is reported to be the second most important mushrooms in production in the world of which $25 \%$ of the total world production of cultivated mushrooms are Pleurotus. Pleurotus as a class of edible mushroom has the capacity to convert nutritionally valueless substances into high protein food and are reputed to have a high saprophytic ability and to grow on a variety of cellulosic wastes (Yildiz et al., 2002). Pleurotus sp., a wood-rot fungus, is cultivated by the application of various heat treatments on the substrates to eliminate competitive fungi like Altemaria sp., Aspergillus sp., Fusarium sp., Monilia sp., Mucor sp., Rhizopus sp. e.t.c. to mention but few. Also, the mycelial growth of this specie is fast and various lignocellulosic waste products can as well be used as culture substrate (Yildiz et al., 2002). Pleurotus ostreatus, is among the edible mushrooms consumed in the tropical states of west African and It is used as spice in vegetable soups and also fried to serve as meat (Iwalokun et al., 2007). They have been relished as a delicacy for centuries because of their subtle flavor, nice aroma and physical taste appeal (Sabir et al., 2003). Apart from being famous for its appetizing flavour, it also offers itself as a potential protein source, minerals and vitamins (Wahid et al., 1988). However, Trichoderma sp., soil filamentous fungi, are antagonists that can cause extensive losses in mushroom production (Jandaik and Guleria, 1999). These fungi produce several enzymes involved in degradation of the fungal cell walls that may contain chitinases and glucanases (Ait-Lahssen et al., 2001). Therefore the most important step for successful cultivation of Pleurotus spp. is the preparation of lignocellulosic material to ward off saprophytic fungi which compete with the mushroom fungus during spawn run (Velazquez-Cedeno, 2008).

In general, the bran and straw of the family of graminae (rice bran, wheat bran, wheat straw, sorghum straw, maize straw) and cotton wastes have been in use for the 
cultivation of $P$. ostreatus in Nigeria. The low availability of these materials for the cultivation of this mushroom in recent years however has led to the search for an alternative source of raw materials as substrates for the cultivation of this specie of mushroom. Attention has therefore been turned into the sawdusts of tropical trees from our saw-mills which of course have been yielding tremendous results. Also, there is a dearth of information on the fundamental processes governing the growth of $P$. ostreatus on sawdust of the tropical trees as substrates. The objective of this study has therefore focused mainly on the investigation of the anti-growth factors of the mycelium of $P$. ostreatus particularly in a submerged liquid fermentation and also the possible and practical steps to take on how it could be surmounted.

\section{MATERIALS AND METHODS}

\section{Medium preparation}

Two media were used for the experiment: extracts from Spondias mombin sawdust and Pycnanthus angolensis sawdust. One hundred gram of sawdust of each was screened and soaked with $500 \mathrm{~mL}$ of deionized water. The sawdust was sterilized with the water and filtered immediately after sterilization using a sterile muslin cloth. The media were prepared according to the modified method of Gbolagade (2004) by dissolving the following chemicals in a $250 \mathrm{~mL}$ of deionized water: glucose, $10 \mathrm{~g}$; ammonium citrate, $0.75 \mathrm{~g} ; \mathrm{KH}_{2} \mathrm{PO}_{4}, 0.25 \mathrm{~g} ; \mathrm{MgSO}_{4} .7 \mathrm{H}_{2} \mathrm{O}$, $0.125 \mathrm{~g} ; \mathrm{ZnSO}_{4} \cdot 7 \mathrm{H}_{2} \mathrm{O}, 0.75 \mathrm{mg} ; \mathrm{FeSO}_{4} .7 \mathrm{H}_{2} \mathrm{O}, 0.75 \mathrm{mg}$; To the solution was added a mixture of vitamins containing thiamine, niacin, riboflavin, biotin, pyridoxine, and folic acid, each at the rate of $50 \mu \mathrm{g} / \mathrm{L}$.

\section{Submerged cultured of mycelium}

The mycelium of $P$. ostreatus used in the investigation was obtained from the Microbiology Research Laboratory of the Federal university of Technology, Akure, Nigeria. The mycelium was resuscitated by inoculating an actively growing mycelial disc into a flask containing $100 \mathrm{ml}$ of extract from the sawdust. Culture was incubated in a rotary shaker (WSZ-100A Model) at $25^{\circ} \mathrm{C}, \mathrm{pH} 5.0$ and agitation speed of $150 \mathrm{rpm}$ for $72 \mathrm{~h}$. This was used as stock medium.

\section{Source of inoculums}

A fungus Kutilakesopsis macalpineae and a bacterium Pseudomonas tolaasii both isolated from infected substrate during solid state fermentation were used.

\section{Effect of temperature on the mycelial growth of $P$.} ostreatus in a submerged culture

Ten millimeter of double strength Potato Dextrose Broth was added to equal volume of buffer solution in test tubes to give $20 \mathrm{~mL}$. Five $\mathrm{mL}$ of stock medium was inoculated after sterilization. The test tubes were incubated at varying temperatures of $21^{\circ} \mathrm{C}, 23^{\circ} \mathrm{C}, 25^{\circ} \mathrm{C}, 27^{\circ} \mathrm{C}, 29^{\circ} \mathrm{C}$, $31^{\circ} \mathrm{C}, 33^{\circ} \mathrm{C}$, and $35^{\circ} \mathrm{C}$. Growth in terms of turbidity was measured on daily basis for $168 \mathrm{~h}$ at $540 \mathrm{~nm}$ wavelength using spectrophotometer (Spectrumlab 22pc model).

\section{Effect of $\mathrm{pH}$ on the mycelial growth of $P$. ostreatus in a submerged culture}

Citrate-Phosphate buffer solution of 4.0, 4.5, 5.0, 5.5, 6.0, $6.5,7.0,7.5$, and 8.0 were prepared (Gbolagade, 2004). Ten millimeter of double strength PDB was added to equal volume of buffer solution in test tubes to give $20 \mathrm{ml}$. Five millimeter of stock medium was inoculated after sterilization. The test tubes were incubated and growth in terms of turbidity was measured on daily basis for $168 \mathrm{~h}$ at $540 \mathrm{~nm}$ wavelength using spectrophotometer (Spectrumlab 22pc model).

\section{Detection of antagonistic activity}

Conventional streak method described by Fakoya et al, (2009) was used for this assay. With the use of a sterile cork borer of $7 \mathrm{~mm}$ diameter, an actively growing edge of a 4-day old mycelial culture of $P$. ostreatus was aseptically cut and placed at the center of a PDA plate. Forty millimeter streak of test organisms $(P$. tolaasii and $K$. macalapinaeae ) was made from a $24 \mathrm{~h}$ and $72 \mathrm{~h}$ old culture of $P$. tolaasii and $K$. macalapinaeae respectively, $23 \mathrm{~mm}$ away from the center of the Petri-dish. The plates were incubated for $168 \mathrm{~h}$ at $25^{\circ} \mathrm{C}$ for the fungus and 37 ${ }^{\circ} \mathrm{C}$ for the bacterium respectively. The percentage inhibition and inter-colony distance were measured on daily basis.

Inhibitory activities of test antagonists on the mycelium growth of $P$. ostreatus in a submerged culture

Ten millimeters of PDB was dispensed into a screw capped test tubes and were sterilized at $121^{\circ} \mathrm{C}$ for $15 \mathrm{~min}$ and allowed to cool before inoculation. Five millimeters of stock medium (mycelium in broth culture) and the test organisms (antagonists) each were inoculated into the test tubes. The treatment was carried out in triplicate while the control tube was left without any inoculum. Growth in terms of turbidity was measured on daily basis for $168 \mathrm{~h}$ at $540 \mathrm{~nm}$ wavelength using spectrophotometer (Spectrumlab 22pc model).

\section{RESULTS AND DISCUSSION}

Inhibitory effect of test antagonists against the mycelial growth of $P$. ostreatus

A gradual increase in the percentage inhibition of $K$. macalpineae and $P$. tolaasii against mycelium of $P$. ostreatus in the submerged fermentation process was observed as shown in Figures 1 and 2. Also, the percentage inhibition and the inter-colony distances between the antagonists and the mycelium in vitro were 
shown in Figures 3 and 4 respectively.

Effect of temperature on the mycelial growth of $P$. ostreatus

Figure 5 showed how temperature was varied during the fermentation processes in order to ascertain the optimum temperature that best enhanced mycelial growth of the mushroom. This was observed to be $25^{\circ} \mathrm{C}$.

\section{Effect of $\mathrm{pH}$ on the mycelial growth of the mushroom}

Table 1 showed the effect of varying $\mathrm{pH}$ during the course of the fermentation processes as the optimum $\mathrm{pH}$ was recorded at 4.5 for the mycelial growth of the mushroom.

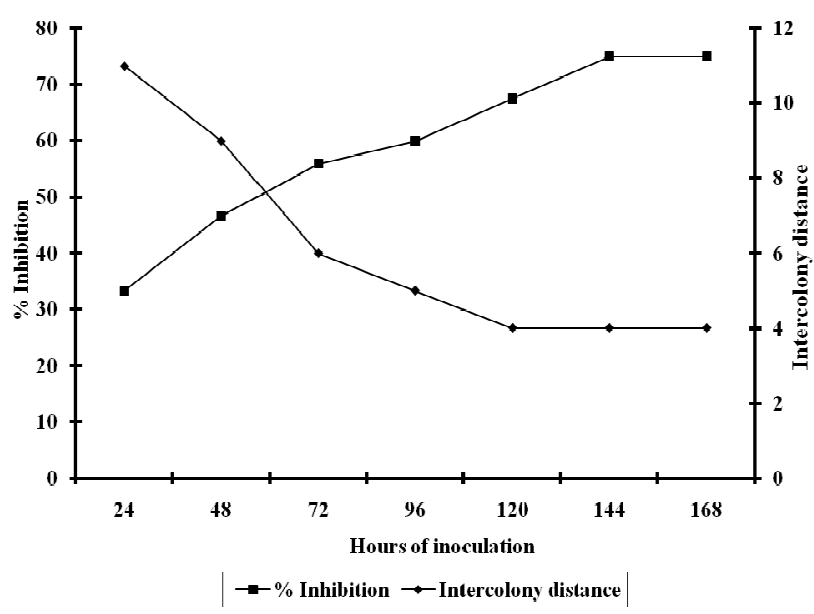

Figure 1: Antagonistic ability of $K$. macalpineae on the mycelial growth of $P$. ostreatus in a submerged culture

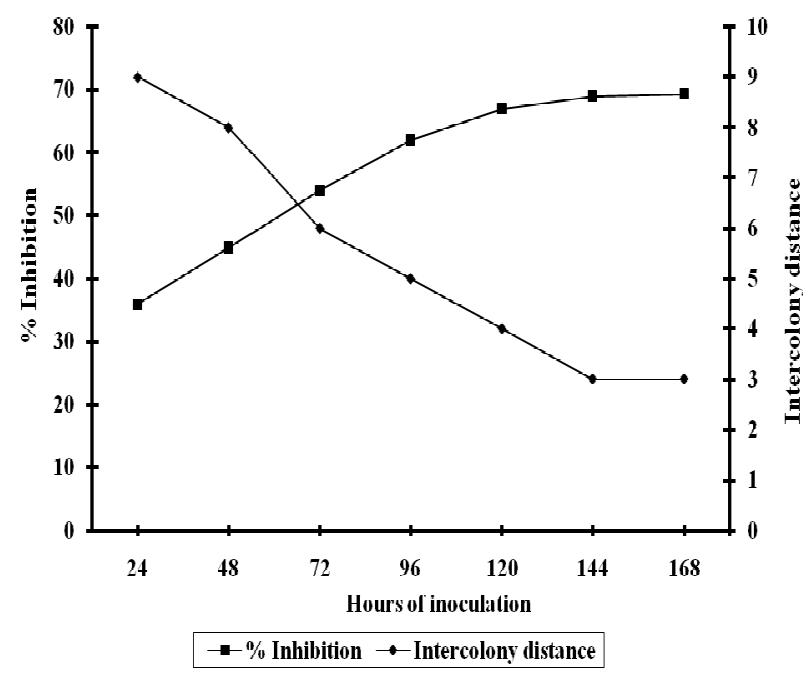

Figure 2: Antagonistic ability of $P$. tolaasii on the mycelial growth of $P$. ostreatus in a submerged culture

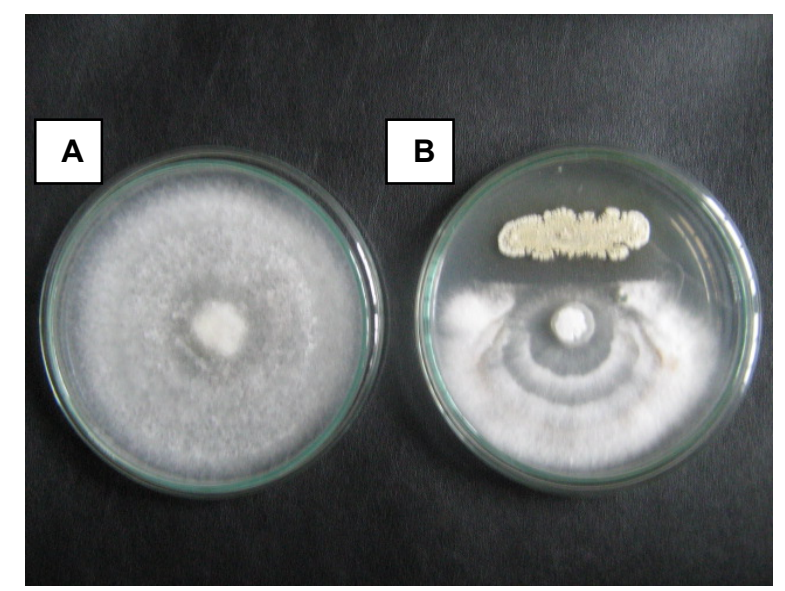

Figure 3: Antagonistic activities of $K$. macalpineae on mycelial growth of $P$. ostreatus. (Photograph taken 7 days after inoculation)

Plate A - Control

Plate B - Conventional streak method

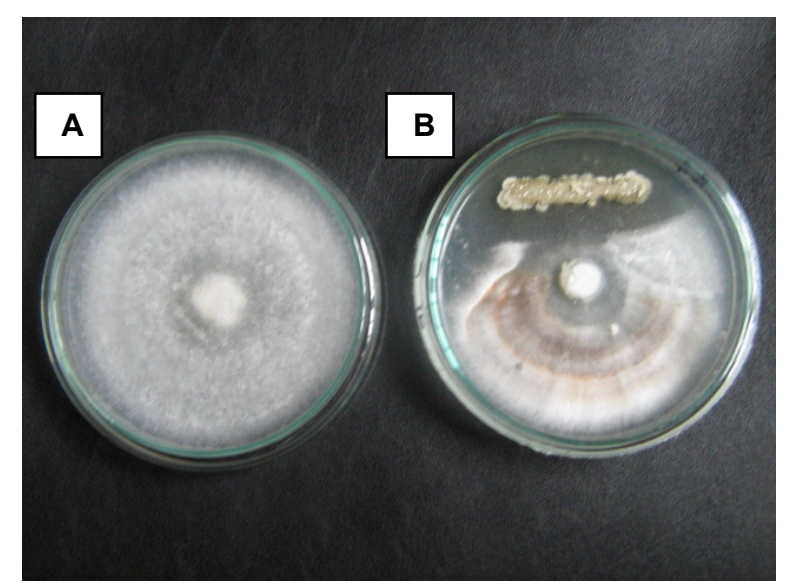

Figure 4: Antagonistic activities of $P$. tolaasii on mycelial growth of $P$. ostreatus. (Photograph taken 7 days after inoculation)

Plate A - Control

Plate B - Conventional streak method

Inhibitory effect of $K$. macalpineae and $P$. tolaasii on the mycelial growth

The pronounced effect of the presence of the test antagonists on the optical density of the mycelial growth of $P$. ostreatus was shown in Figure 6 as the growth was greatly impaired during submerged fermentation process due to the presence of the test antagonists.

The ability of $K$. macalpineae and $P$. tolaasii to inhibit mycelium growth of Pleurotus is a great threat to the cultivation of $P$. ostreatus. However, Figure 1 and $\mathbf{2}$ show the gradual increase of the percentage inhibition of $K$. macalpineae against mycelium of $P$. ostreatus from 33.3 $\%$ at $24 \mathrm{~h}$ to $75.0 \%$ at $168 \mathrm{~h}$ in the conventional streak method. Also the percentage of inhibition of $P$. tolaasii against the mycelium of $P$. ostreatus increased gradually 


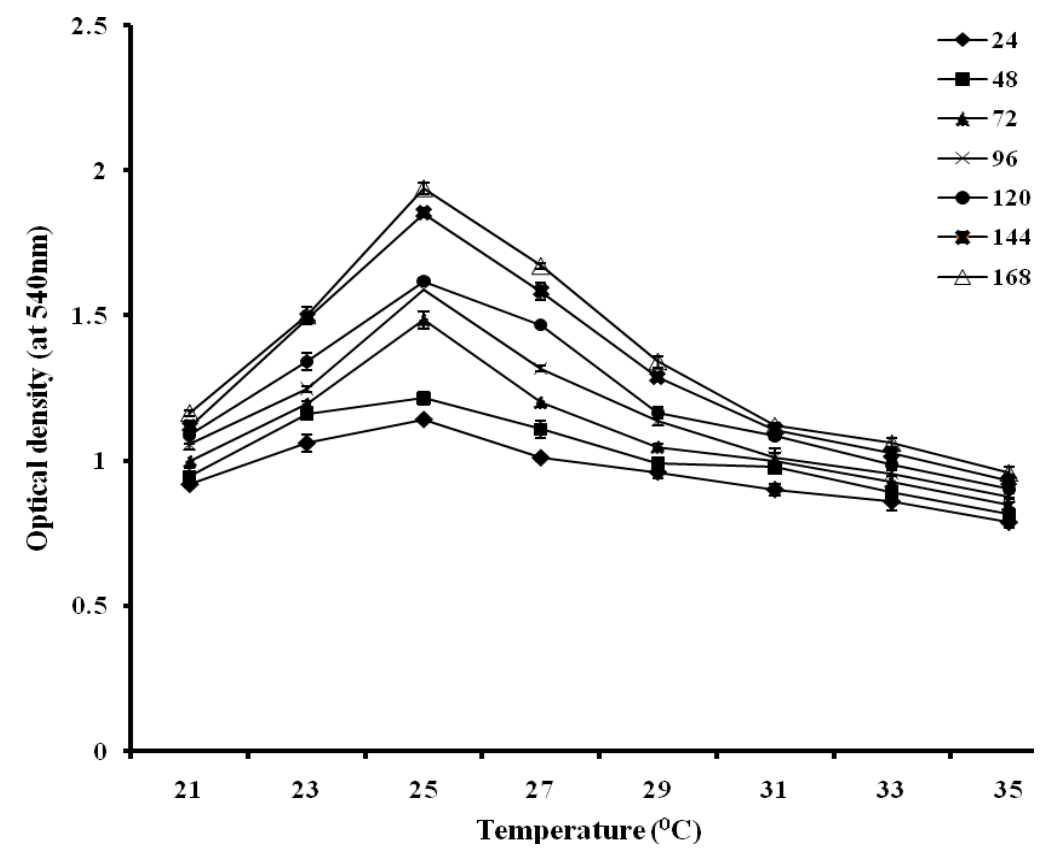

Figure 5: Effect of temperature on the mycelial growth of $P$. ostreatus in a submerged culture (absorbance at 540nm)

Table 1: Effect of $\mathrm{pH}$ on the optical density of mycelial growth of $P$. ostreatus in a submerged culture (absorbance at 540nm)

\begin{tabular}{|c|c|c|c|c|c|c|c|}
\hline \multirow{2}{*}{$\begin{array}{c}\mathrm{pH} \\
\text { values }\end{array}$} & \multicolumn{7}{|c|}{ Hours of incubation } \\
\hline & 24 & 48 & 72 & 96 & 120 & 144 & 168 \\
\hline 4.0 & $0.612 \pm 0.02^{\mathrm{d}, \mathrm{e}}$ & $0.654 \pm 0.00^{e}$ & $0.698 \pm 0.01^{\mathrm{e}}$ & $0.718 \pm 0.02^{\dagger}$ & $0.732 \pm 0.01^{\dagger}$ & $0.766 \pm 0.00^{\mathrm{e}, \mathrm{f}}$ & $0.794 \pm 0.00^{\mathrm{e}, \mathrm{f}}$ \\
\hline 4.5 & $0.756 \pm 0.01^{e, f}$ & $0.787 \pm 0.01^{\mathrm{e}, \mathrm{f}}$ & $0.819 \pm 0.00^{\dagger}$ & $0.841 \pm 0.01^{\dagger}$ & $0.866 \pm 0.00^{f}$ & $0.967 \pm 0.01^{\mathrm{g}}$ & $0.998 \pm 0.01^{\mathrm{g}}$ \\
\hline 5.0 & $0.644 \pm 0.00^{\mathrm{e}}$ & $0.664 \pm 0.0^{\mathrm{e}}$ & $0.687 \pm 0.02^{\mathrm{e}}$ & $0.699 \pm 0.01^{\mathrm{e}}$ & $0.720 \pm 0.01^{\dagger}$ & $0.753 \pm 0.02^{\mathrm{e}, \mathrm{f}}$ & $0.788 \pm 0.01^{\mathrm{e}, \mathrm{f}}$ \\
\hline 5.5 & $0.567 \pm 0.02^{d}$ & $0.587 \pm 0.01^{d}$ & $0.603 \pm 0.01^{\mathrm{d}, \mathrm{e}}$ & $0.619 \pm 0.00^{\mathrm{d}, \mathrm{e}}$ & $0.646 \pm 0.02^{\mathrm{e}}$ & $0.658 \pm 0.01^{\mathrm{e}}$ & $0.671 \pm 0.00^{\mathrm{e}}$ \\
\hline 6.0 & $0.502 \pm 0.01^{\mathrm{c}, \mathrm{d}}$ & $0.519 \pm 0.00^{\mathrm{c}, \mathrm{d}}$ & $0.532 \pm 0.02^{c, d}$ & $0.554 \pm 0.01^{\mathrm{c}, \mathrm{d}}$ & $0.579 \pm 0.00^{d}$ & $0.598 \pm 0.01^{d}$ & $0.602 \pm 0.01^{d}$ \\
\hline 6.5 & $0.468 \pm 001^{\mathrm{c}}$ & $0.479 \pm 0.01^{\mathrm{c}}$ & $0.491 \pm 0.00^{c}$ & $0.504 \pm 0.02^{\mathrm{c}, \mathrm{d}}$ & $0.518 \pm 0.01^{\mathrm{c}, \mathrm{d}}$ & $0.534 \pm 0.00^{\mathrm{c}, \mathrm{d}}$ & $0.542 \pm 0.00^{c}$ \\
\hline 7.0 & $0.405 \pm 0.00^{b, c}$ & $0.422 \pm 0.01^{\mathrm{b}, \mathrm{c}}$ & $0.438 \pm 0.01^{\mathrm{c}}$ & $0.453 \pm 0.01^{\mathrm{c}}$ & $0.469 \pm 0.01^{\mathrm{c}}$ & $0.482 \pm 0.01^{\mathrm{c}}$ & $0.495 \pm 0.01^{\mathrm{c}}$ \\
\hline 7.5 & $0.323 \pm 0.01^{\mathrm{b}}$ & $0.337 \pm 0.00^{\mathrm{b}}$ & $0.349 \pm 0.01^{\mathrm{b}}$ & $0.358 \pm 0.01^{\mathrm{b}}$ & $0.370 \pm 0.00^{\mathrm{b}, \mathrm{c}}$ & $0.382 \pm 0.02^{\mathrm{b}, \mathrm{c}}$ & $0.393 \pm 0.01^{\mathrm{b}, \mathrm{c}}$ \\
\hline 8.0 & $0.272 \pm 0.00^{\mathrm{a}}$ & $0.285 \pm 0.01^{a}$ & $0.298 \pm 0.02^{\mathrm{a}}$ & $0.306 \pm 0.00^{a, b}$ & $0.318 \pm 0.01^{a, b}$ & $0.328 \pm 0.01^{\mathrm{b}}$ & $0.337 \pm 0.00^{\mathrm{b}}$ \\
\hline
\end{tabular}

Values are means of triplicates $\pm S D$, Samples carrying the same superscripts are not significantly different at $(p>0.05)$

from $37.5 \%$ at $24 \mathrm{~h}$ to $70.7 \%$ at $168 \mathrm{~h}$ in the conventional streak method. The gradual increase in the percentage inhibition and decrease in the inter-colony distances between the antagonists and the mycelium in vitro (Figures 3 and 4) is a clear indication of their ability to implicate good yield production of the mushroom during solid state fermentation. The inter-colony distance between the mycelium and the antagonist streak and the degree of growth rate inhibition as observed in this study supported the view that antagonism results from the active production of a diffusible antimicrobial compound by the microorganisms. These results are in agreement with other studies where the inhibitory effects of some bacteria having antifungal properties were the main factor affecting the potential of Pleurotus spp. in ecosystem colonization (De Boer et al., 1998; Savoie et al., 2001). Also some bacterial strains are capable of inhibiting through the production of volatile organic compounds (Mackie and
Wheatley 1999) or by releasing antibiotics (Nielsen et al., 2000). These compounds can provoke cell perturbations at the membrane structure level and Pseudomonas spp. have been identified as one of such antagonists (Ellis et al., 2000). However, colonization of the mycelium of $P$. ostreatus was strongly established in this work to be affected adversely by the presence of some bacteria and fungi in its cultivation substrate when cultivated on pasteurized or unsterilized substrate as compared to that sterilized. Therefore, an uninterrupted colonization of mycelium could be achieved by proper sterilization of the substrate(s) or media used for the mycelium propagation of the mushroom. As a matter of fact, an ideal sterility should also be maintained during spawn inoculation as well as the during mycelium colonization of the substrate.

The effect of temperature was greatly pronounced on the growth of mycelium of $P$. ostreatus as the optimal growth 


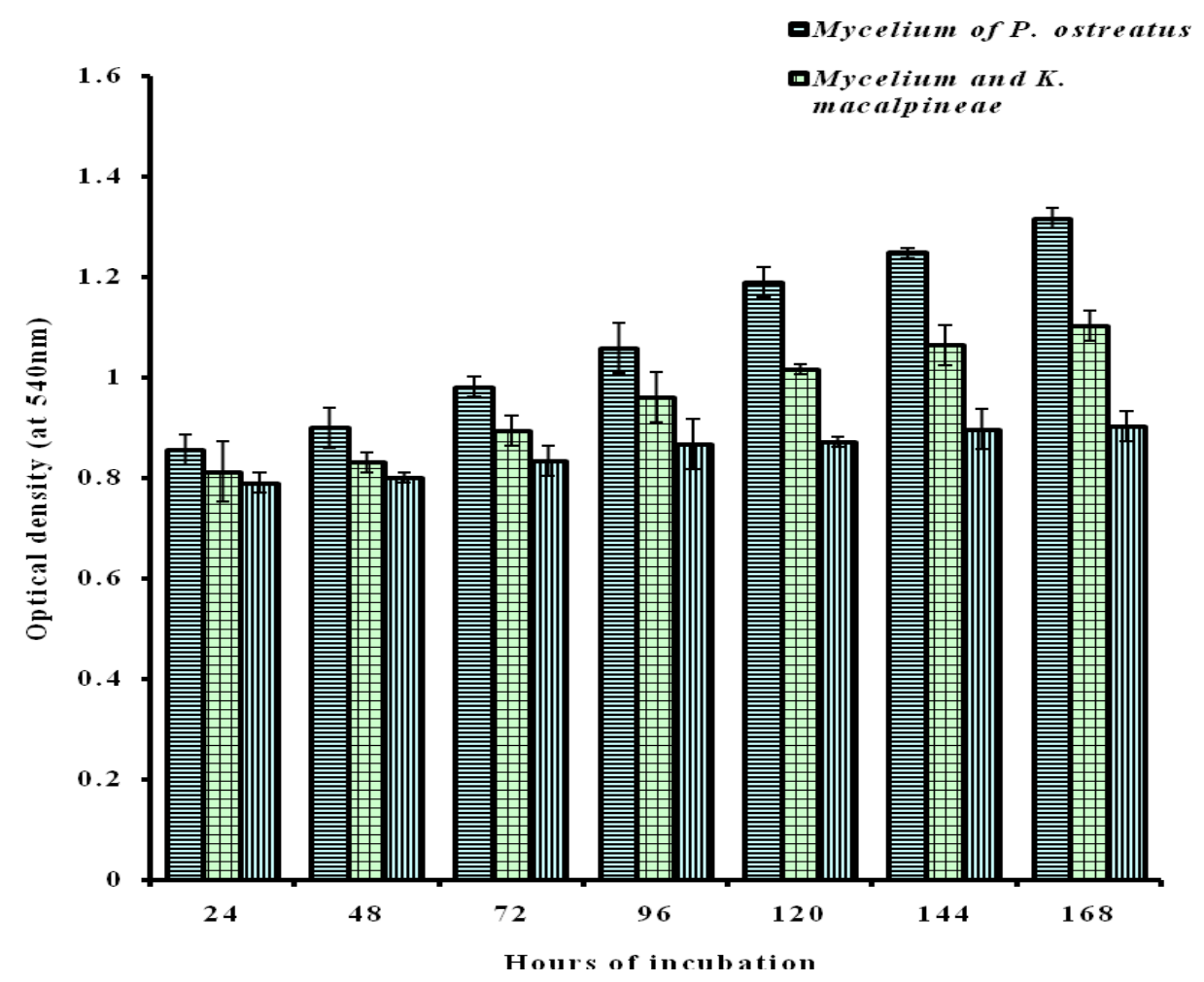

Figure 6: Inhibitory effects of K. macalpinaeae and $P$. tolaasii on the mycelial growth of $P$. ostreatus in a submerged culture.

was observed at $25{ }^{\circ} \mathrm{C}$ (Figure 5). This suggests that substrate colonization is at its best at this temperature. Table 1 also show the effect of $\mathrm{pH}$ on the mycelium growth as the optimal proliferation of the mycelium growth of $P$. ostreatus was observed at 4.5 and this suggests that colonization of mycelium of mushroom performs best at aslightly acidic medium. This confirms the findings of Bello and Akinyele (2007) that increase in fungal count throughout the period of fermentation may be due to the optimum $\mathrm{pH}$ obtained because fungi are only tolerant to acid.

The inhibitory effect of $K$. macalpineae and $P$. tolaasii on the mycelium growth was shown in Figure 6. It was observed that the test antagonists had significant effects on the growth and colonization of the mycelium in vitro in a submerged culture as the optical density increased appreciably in the absence of the test antagonists. This however suggests that the organisms could presents itself as an antigrowth bio-factor even in a solid state fermentation.

Furthermore, this study has shown the role of the microflora of the culture substrate in mushroom cultivation, therefore it is necessary to improve the technology in substrates treatment in order to eliminate possible antagonist that could inhibit the growth and the development of edible mushroom, thus producing better yields. In further studies, the fungus and the bacterium involved in the antagonistic phenomenon in this research work could be screened and characterized for their biocontrol activities particularly against poisonous and pathogenic micro and macro-fungi as well as pathogenic and harmful bacteria.

\section{CONCLUSION}

Some of the observed important bio-factors during the course of this study that can adversely affect the growth of mycelium and invariably implicate successful cultivation of $P$. ostreatus are the temperature, $\mathrm{pH}$ and improper sterilization of the substrates used in the cultivation. Therefore, if adequate and proper care is taken during the course of $P$. ostreatus cultivation, all these biological banes could be averted.

\section{REFERENCES}

Ait-Lahsen, H., Soler, A., Rey, M., De la Cruz, J., Monte, E. and Llobell, A. (2001). An antifungal exoalpha-1,3-glucanase (AGN 13.1) from the biocontrol fungus Trichoderma harzianum. Applied Environmental Microbiology, 67: 5833-5839.

Bello, B. K and Akinyele, B. J. (2007). Effect of Fermentation on the Microbiology of and Mineral Composition of an Edible Mushroom Termitomyces 
robustus (Fries). International Journal of Biological Chemistry, 4: 237-243

Chang, S.T. (1999). World production of cultivated and medicinal mushrooms in 1997 with particular emphasis on Lentinula edodes (Berk.) Sing. in China. International Journal of Medicinal Mushroom. 1: 291300.

De Boer, W., Klein Gunnewiek, P. J. A., Lafeber, P., Janse, J. D., Spit, B. E. and Woldendorp, J. W. (1998). Antifungal properties of chitinolytic dune soil bacteria. Soil Biology and Biochemistry. 30: 193-203.

Ellis, R. J., Timms-Wilson, T. M and Bailey, M. J. (2000). Identification of conserved traits in fluorescent pseudomonads with antifungal activity. Environmental Microbiology. 2: 274-284.

Fakoya, S., Fakoya, A., Adetuyi, F. C and Akinyosoye, F. A. (2009). Antifungal Activities of Microbial Isolates from Sweet Cassava (Manihot palmata, Crantz) Starch. International Journal of Applied and Environmental Science. 4(2): 151-160.

Gbolagade, J.S., (2004). Bacteria associated with cultures of Psathyrella atroumbonata (Pegler) and Schizophyllum commune (Fr. Ex. Fr.). African Journal of Biomedical Research. 7: 139-143.

Iwalokun, B. A.., Usen, U. A., Otunba, A. A and Olukoya, D. K. (2007). Comparative phytochemical evaluation, antimicrobial and antioxidant properties of Pleurotus ostreatus. African Journal of Biotechnology. 6 (15): 1732-1739.

Jandaik, S and Guleria, D. S. (1999). Yield loss in Agaricus bisporus due to Trichoderma infection. Mushroom Research. 8: 43-46.

Kuforiji, O. O. (2006). Vegetative growth requirements of V. volvacca a Nigerian Mushroom. Journal of Applied Sciences. 9(2): 6309-6315.

Mackie, A.E and Whetley, R. E. (1999). Effects and incidence of volatile organic compound interactions between soil bacterial and fungal isolates. Soil Biology and. Biochemistry 3: 375-385.

Nielsen, T.H., Thrane, C., Christophersen, C., Anthoni, $U$ and Sorensen, J. (2000). Structure, production characteristics and fungal antagonism of tensin-a new antifungal cyclic lipopeptide from Pseudomonas fluorescens strain 96.578. Journal of Applied. Microbiology. 89: 992-1001.

Sabir, S. M., Hayat, I., I. Hussain, I. and Gardesi, S.R.A. (2003). Proximate analysis of Mushroom Azad Kashmir. Pak. Journal of Plant Pathology. 2 (2): $97-$ 101.

Savoie, J. M., Mata, G and Mamoun, M. (2001). Variability in brown line formation and intracellular laccase production during interaction between whiterot basidiomycetes and Trichoderma harzianum biotype. Mycologia. 93: 243-248.

Velazquez-Cedeno, M., Farnet, A. M., Mata, G and J.M. Savoie, J. M. (2007). Interspecific interactions with Trichoderma longibrachiatum induce Pleurotus ostreatus defence reaction based on the production of laccase isoenzymes. Biotechnology Letters. 29: 1583-1590.

Velazquez-Cedeno, M., Farnet, A. M., Mata, G and J.M. Savoie, J. M. (2007). Role of Bacillus spp. in antagonism between Pleurotus ostreatus and Trichoderma harzianum in heat-treated wheat-straw substrates. Bioresource Technology. 99: 6966-6973.

Wahid, M., Sattar, A and Khan, S. (1988). Composition of wild and cultivated mushrooms of Pakistan. Mushroom in Tropics. 8: 47-51.

Yildiz S., ü. Cafer., Derya-Gezer, E. and Temiz, A. (2002). Some lignocellulosic wastes used as raw material in cultivation of the Pleurotus ostreatus culture mushroom. Process Biochemistry. 38: 301306. 